\title{
Metro systems in Europe: a comparison of the Copenhagen and Bucharest metros
}

\author{
T. Holvad \\ European Railway Agency \& Transport Studies Unit, \\ University of Oxford, UK
}

\begin{abstract}
Across Europe a substantial number of metro systems have been constructed in major cities during the last three decades, e.g. Seville (2009) Duisburg (1992), Lille (1983) and Prague (1974). Metros offer large urban areas significant increases in the capacity of the public transport systems both in terms of quantity and quality but on the other hand require substantial capital costs. Therefore, careful consideration to the expected usage and benefits delivered of a metro system should be undertaken in order to ensure the economic feasibility. In this paper two metro systems will be examined: the Copenhagen Metro and the Bucharest Metro. The Copenhagen Metro was opened in 2002 and the Bucharest was opened in 1979. These two cases are interesting as they can highlight differences regarding metro systems in Eastern and Western Europe. Key information regarding both metros will be highlighted in terms of background to the decision of developing the metro systems, construction and financing arrangements, current operations and plans for future extensions. Further assessment regarding the integration of the metro within the overall public transport system will be given, incl. ticketing and information integration as well as the interchange facilities. Particular focus will be on the impacts of the metro systems in terms of patronage and modal shift effects as well as consideration to the possible wider economic implications.
\end{abstract}

Keywords: passenger transportation, metro systems, European context, Copenhagen, Bucharest. 


\section{Introduction}

Metro systems allow for high carrying capacity (30,000 passengers per hour per direction) and also higher commercial speeds than alternative public transport systems such as light rail and tram (UITP [1]). Furthermore, there are also advantages linked to availability, reliability and punctuality. These characteristics imply that metro rail systems can provide possible solutions to the increased transportation problems in urban areas (congestion for road based traffic, environmental concerns and road safety). However, metro systems are also expensive and would in general require a large population to be viable from an economic perspective, typically the capital city of a country (together with other cities with population larger than 1 million). Obviously, this problem is compounded by possibility for cost overruns for urban rail and metro projects (Flyvbjerg [2]).

In the context of this paper we are using the UITP [1] definition of a metro system: 'A tracked, electrically driven local means of transport, which has an integral, continuous track bed of its own (large underground or elevated sections)'. As such this definition excludes light rail as well as tram and commuter rail systems. The main distinguishing factor between a metro system and a light rail or tram is the separation from other traffic.

This paper aims to examine the two specific examples of metro systems in Europe: Copenhagen Metro and Bucharest Metro. As such this comparison is of interest reflecting on different socio-economic, geographical and operational contexts. In both cases there is ongoing expansion of the systems in order to address the transportation needs and tackle the sustainability problems.

The paper is structured as follows: Section 2 provides introductory and background information concerning metro system construction and development in Europe. In Section 3 the Copenhagen Metro is presented and key elements outlined, while Section 4 contains similar information for the Bucharest Metro. Concluding remarks are included in Section 5.

\section{Metro construction and operation: European context}

In recent years there has been a substantial expansion of metro systems along with light rail, light metro and tram schemes across Europe (as well as worldwide). Table 1 provides an overview of the situation in 2004 in the different European countries (UITP [1]). In total there were some 36 systems with 138 lines that comprised a network length of over $2300 \mathrm{~km}$. At that point in time (2004) there were also additional schemes under construction or at an advanced planning stage. These schemes include both completely new systems as well as expansion of already existing systems. Overall, some 20 new systems were in 2004 either under construction (7) or at the planning stage (13). Together with the expansion of existing networks this would imply an increase in total network size of $21 \%$ of which 135 route $\mathrm{km}$ were for schemes already under construction and 503 route $\mathrm{km}$ involved projects under planning. 
Since 2004 several completely new metro systems have been opened, e.g. Turin in 2006 and Seville in 2009. In other cities new lines to already existing systems have been taken into operation (e.g. Lausanne 2008 and Berlin 2009). A number of other metro schemes are under construction (e.g. Thessaloniki and Dublin) or advanced planning.

Table 1: $\quad$ Metro systems in Europe.

\begin{tabular}{|c|c|c|c|c|}
\hline Country & $\begin{array}{c}\text { Year of opening } \\
(*)\end{array}$ & Systems & Lines & Track km \\
\hline Austria & 1898 & 1 & 5 & 61 \\
\hline Belgium & 1969 & 1 & 3 & 84 \\
\hline Finland & 1982 & 1 & 11 & 76 \\
\hline Denmark & 2002 & 1 & 2 & 17 \\
\hline France & 1900 & 6 & 27 & 322 \\
\hline Germany & 1902 & 4 & 22 & 361 \\
\hline Greece & 1904 & 1 & 2 & 18 \\
\hline Italy & 1955 & 2 & 8 & 144 \\
\hline Netherlands & 1968 & 2 & 4 & 127 \\
\hline Portugal & 1959 & 1 & 4 & 28 \\
\hline Spain & 1919 & 3 & 20 & 349 \\
\hline Sweden & 1950 & 1 & 3 & 110 \\
\hline United Kingdom & 1863 & 3 & 15 & 480 \\
\hline Total & & $\mathbf{2 7}$ & $\mathbf{1 1 7}$ & $\mathbf{2 0 7 2}$ \\
\hline Czech Republic & 1974 & 1 & 3 & 50 \\
\hline Hungary & 1896 & 1 & 3 & 32 \\
\hline Poland & 1995 & 1 & 1 & 11 \\
\hline Total & & $\mathbf{3}$ & 7 & $\mathbf{9 3}$ \\
\hline Bulgaria & 1998 & 1 & 1 & 6 \\
\hline Norway & 1966 & 1 & 5 & 80 \\
\hline Romania & 1979 & 1 & 4 & 63 \\
\hline Switzerland & 1991 & 1 & 2 & 10 \\
\hline Turkey & 1997 & 2 & 2 & 22 \\
\hline Total & & $\mathbf{6}$ & $\mathbf{1 4}$ & $\mathbf{1 8 1}$ \\
\hline$*$ & & & \\
\hline
\end{tabular}

Source: UITP [1]

Note: (*) The opening year refers to the year when the first metro in a country opened (in case there is more than one metro system in that country).

In parallel expansion of the rolling stock fleet for metro systems are also envisaged over the coming years. A consultancy study prepared for the Commission (DG TREN) in the context of the EC Green Paper on Urban Transport 2007 it was mentioned that 14,000 units (cars) would be required for the period $2000-2020$ [3]. 
The recent and continued network expansion of metros in Europe are developed and funded by national, regional and local government authorities and supported by the EU including funding from EIB, EBRD and EU regional and structural funds (e.g. in June 2010 it was announced that EIB would provide a credit facility towards the extension of the Athens Metro).

\section{Copenhagen metro: case study I}

\subsection{Overview of system}

Until 2002 no metro system existed in Denmark, although the so-called S-Train (S-tog) providing sub-urban / urban rail services in the Greater Copenhagen Area included a metro-like section in the Copenhagen City Centre. However, in October 2002 the first metro system (Copenhagen Metro) opened in Copenhagen providing services between the City Centre (Nørreport) and Amager along two routes, see Figure 1. Subsequently, the system has been expanded in two additional stages such that the densely populated areas west of the city centre are connected to the City centre and Amager (where Copenhagen International Airport, Kastrup, is located and now served by the Metro). Currently, the length of the system is 21 kilometres of which 10 kilometres are tunnelled and the remainder consists of elevated tracks. Further expansion is underway with construction work on a City Circle Line (Cityringen) which is expected to open in 2018.

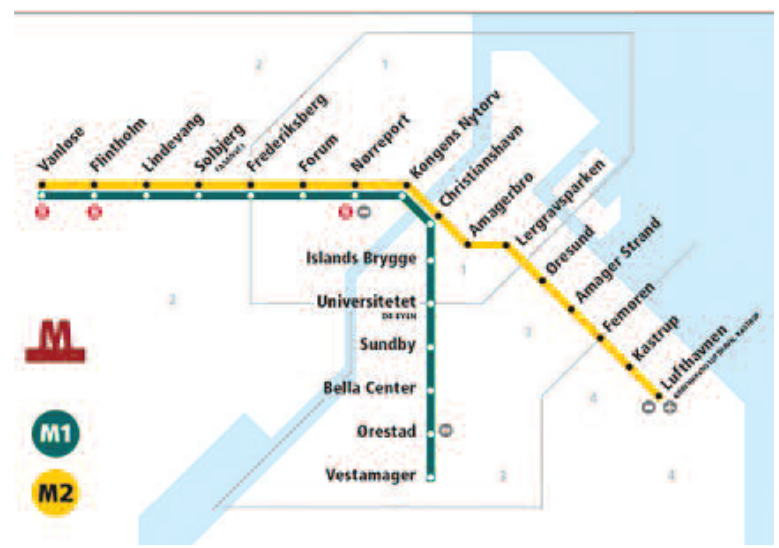

Source: http://www.sputnicproject.eu/

Figure 1: Copenhagen metro - network map.

\subsection{Background to metro decision}

The key background towards the decision for a metro system in Copenhagen was the possibility for development of largely undeveloped land $(3 \mathrm{sq} \mathrm{km})$ some 5 $\mathrm{km}$ from the City Centre. This area had mainly been used by the Danish military 
for training purposes. A Consortium (Ørestadsselskabet I/S) was set up in 1992 with two main tasks: 1) develop and sell the land for housing, office and business, schools and education institutions etc; 2) use the revenue from the real estate sale to construct the Metro system. Ørestadsselskabet was owned by Copenhagen Municipal (55\%) and the Danish state (45\%). Other options than metro were considered, including light rail. The choice for a (light) metro system was taken among other reason for the view that it would involve relative lower operational costs and relative better possibilities to attract passengers.

\subsection{Construction and financing}

Following the principal positive decision by the Danish Parliament through passing the Orestad Act in 1992 construction of the Copenhagen Metro commenced in November 1996. Overall, the construction was organised in three phases:

- Phase 1: City centre (Nørreport) to Amager with branches to West Amager (Ørestad), M1 and East Amager, M2. Services opened in October 2002

- $\quad$ Phase 2: Extension of the common M1 / M2 section from Nørreport to Western Copenhagen. The extended network opened in May and October 2003

- Phase 3: This involved extending the M2 line to the Copenhagen International Airport, Kastrup Airport. Services on this part of the network began in September2007.

As such the complete project suffered from significant delays in construction due to among other factors higher than expected complexity regarding station building leading to substantial cost overruns. On the hand, the Metro project benefitted from low interest rates coupled with better than expected real estate sales.

\subsection{Organisational form}

Ownership of the Copenhagen Metro has since 2007 been with Metroselskabet (taking over from Ørestadsselskabet that was discontinued). This company is owned by local authorities $(58,3 \%)$ and the Danish state $(41,7 \%)$. Operation of the metro is subcontracted through tendering and is currently with Ansaldo STS (until 2015) (see Metroselskabet [4]).

\subsection{Current operations and performance}

The 20,5 km metro system consists of two lines (M1 and M2) with some 22 stations. It is a driver-less system with a headway between 2 and 20 minutes according to time / day in the week. The Copenhagen Metro is running services all 24 hours though with reduced frequency during the night. Overall, reliability is at a high level: in 2009 the operational reliability was 98,6\% for the entire year (Metroselskabet [4]). 


\subsection{Extension plans}

A major extension plan is being taken forward through the Circle Line scheme (Cityringen). This scheme will circle the Copenhagen City centre and provide connections to the areas with high populations (Østerbro, Nørrebro, Vesterbro). Transfer from the Circle Line to M1 / M2 is facilitated at two stations. This scheme is under construction and is expected to be completed by 2018. In addition, there are proposals under consideration to expand the Circle Line towards suburbs further afield.

\subsection{Integration for metro}

Our assessment of integration in the Copenhagen Metro will be based on four elements: 1) Integrated information on routes, timetables and fares, 2) integrated ticketing, 3) network integration and 4) wider integration to the rest of the transport system. Similar elements will be used for the Bucharest Metro.

Table 2: $\quad$ Copenhagen metro - integration.

\begin{tabular}{|c|c|}
\hline $\begin{array}{c}\text { Integration } \\
\text { element }\end{array}$ & Remarks \\
\hline Information & $\begin{array}{c}\text { Information about maps, timetables and fares readily } \\
\text { available. Real-time information about Metro services, but } \\
\text { similar information is not available for other modes. }\end{array}$ \\
\hline Ticketing & $\begin{array}{c}\text { Fare structure of the Greater Copenhagen Area for other } \\
\text { public transport modes is also applicable for the Metro. } \\
\text { Metro tickets can be used on other public transport modes } \\
\text { (bus and rail) and vice versa. One type of Multi-ride ticket } \\
\text { card for S-train not valid on the Metro. }\end{array}$ \\
\hline Network & $\begin{array}{c}\text { Interchange facilities within the Metro system as well as } \\
\text { for other public transport modes (bus, long distance and } \\
\text { commuter rail). One problem though is that bus and metro } \\
\text { lines in many places are running in parallel, thereby } \\
\text { possibly limiting passenger numbers on the Metro. }\end{array}$ \\
\hline Wider integration & $\begin{array}{c}\text { Car parking facilities available. Possible to bring bicycles } \\
\text { on the Metro though outside the peak periods. }\end{array}$ \\
\hline
\end{tabular}

\subsection{Patronage and modal split effects}

An overview of trends in patronage is given in Table 3. The Table shows that passenger numbers / passenger kilometres have grown significantly over the period considered. However, despite these positive trends the figures are below the ones initially forecasted when the project was decided upon (Sputnic [5]). 
Table 3: Copenhagen metro patronage, number of passengers and passenger kms, 2002-2009.

\begin{tabular}{|c|c|c|c|c|c|c|c|c|}
\hline & 2002 & 2003 & 2004 & 2005 & 2006 & 2007 & 2008 & 2009 \\
\hline $\begin{array}{c}\text { Passengers } \\
\text { ('000) }\end{array}$ & 3282 & 20379 & 33800 & 36100 & 36500 & 39400 & 46500 & 49800 \\
\hline $\begin{array}{c}\text { Passenger } \\
\text { km (mln.) }\end{array}$ & 9 & 67 & 128 & 162 & 164 & 177 & 195 & 215 \\
\hline
\end{tabular}

Source: Danish Statistical Bureau (online database available at www.dst.dk).

Note: The numbers reported for 2002 do not cover a full calendar year as the Metro only opened on the 19 October 2002. Increased patronage in certain years (2003, 2004 and 2007-2008) linked to expansion of the network length.

On a daily basis the Copenhagen Metro is on average used by 137,000 passengers. Analyses from 2006 suggest that along both Metro corridors the general negative trend in public transport usage had changed to a positive one in 2003 at a level around 7-9\% (Ildensborg-Hansen and Vuk [6]).

\subsection{Wider economic implications of metro}

Evidence is available regarding both some induced trips as well as transfer of already existing trips from other modes incl. car, bus and bicycle (IldensborgHansen and Vuk [6]). In some cases there is evidence that average travel time has reduced which has led to changes in destination choice due to improved accessibility for these destinations (Ildensborg-Hansen and Vuk [6]. These travel time gains are important in terms of economic implications and the socioeconomic balance of the Copenhagen Metro.

\section{Bucharest metro: case study II}

\subsection{Overview of system}

The first line of the Bucharest Metro was opened in 1979 although there have been plans for a rapid transit system since the late 1930s. This provided an important link between areas east and west of the City Centre. During the following years additional sections / lines were added to the network. Currently, there are 4 lines with a total network length of $67 \mathrm{~km}$. This network provides important public transport services for journeys to / from city centre as well as connecting the different areas of Bucharest. On average it is used by some 500,000 passengers per day (Metrorex [7]). Further expansion of the system is being planned including a link to the Bucharest International Airport. Figure 2 shows the current network configuration of the Bucharest Metro system. 


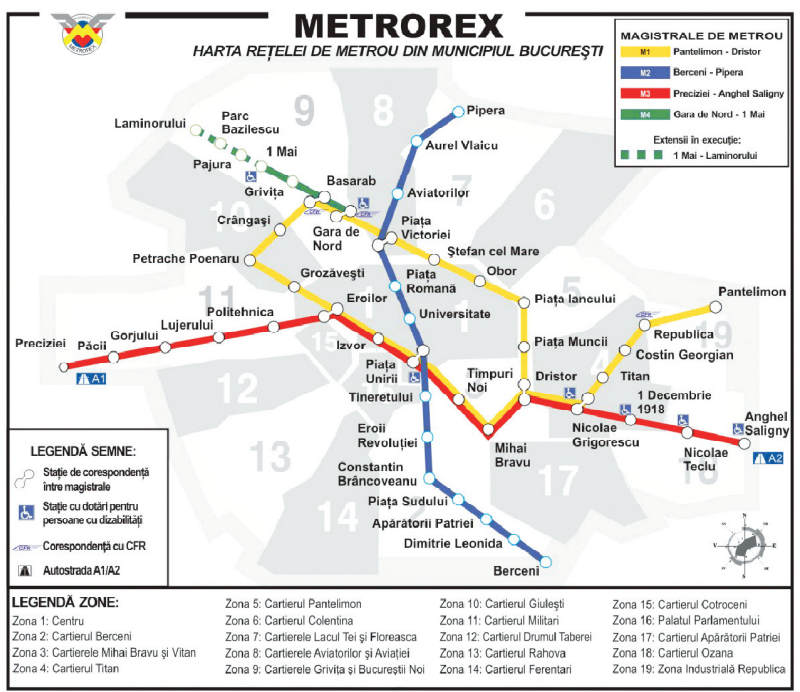

Source: Metrorex [7]

Figure 2: $\quad$ Bucharest metro - network map.

\subsection{Background to metro decision}

The main background to the decision to construct and develop a metro in Bucharest is linked to the strong urban development and population growth that had occurred over the past decades. In 1948 the population of Bucharest was around 1 million but by 1977 the population had increased to 1,8 million. As a result it was perceived that the surface public transport system was insufficient to cater for the existing and future transport needs within the city. A metro system would provide a significant increase in transport carrying capacity due to its rapid transit characteristics.

\subsection{Construction and financing}

Following the opening of the first line (M1) in 1979 that had a length of $6,2 \mathrm{~km}$ this line was gradually extended and additional lines also added to the network. In 1981, 1984, 1987, 1989 and 1990 extensions were opened for the M1 line, a second line (M3) was added in 1981 sharing tracks with M1 on a part of the route. Extensions to M3 were also opened in 1990 and 2008. A North-South line (M2) was added in 1987 and the first part of the fourth line (M4) was opened in 2000. The largest extension of the network occurred in 1981 were some $10,1 \mathrm{~km}$ of lines were opened (M1/M3). As a result of the network extension since 1979 the system today comprises some $67 \mathrm{~km}$ with a total of 49 stations. Financing has usually been secured through government funds supported by EIB and EBRD loans and credit facilities. Increased use of public private partnerships (PPPs) is foreseen for schemes in the future. 


\subsection{Organisational form}

The Bucharest Metro is operated by Metrorex. Metrorex is fully owned by the Romanian state represented by the Ministry of Transports. Over several years there have been plans and considerations to the possibility to create a single transport authority for Bucharest with responsibility for both underground (Metro) and overground (RATB) transport systems. However, to date these plans have not been implemented, although there are a number of steps being taken to ensure an enhanced level of integration of the Metro and other public transport systems (e.g. in the area of ticketing).

\subsection{Current operations and performance}

The Bucharest Metro runs services on the four lines largely underground except for a small section between the last two stations on the M2 line. It is a driverbased system and it is operated with a headway in the peak-periods of between 3 and 7 minutes (the M2 line has the lowest operation interval, 3-5 minutes while the other lines have between 6 and 7 minutes). Outside the peak period the typical headway is between 8 and 10 minutes. Apart from the expansion of the network a substantial rolling stock replacement programme is underway where Bombardier train sets are gradually replacing the older rolling stock (Astra IVA type) that was built between 1976 and 1992.

\subsection{Extension plans}

A number of extension plans are currently being pursued. Most advanced is the extension of the already M4 line which is foreseen to be opened during 2011. Other plans include completely new lines (M5, M6, M7 and M8). In particular, the M6 line is of interest as it would provide rapid transit connection from the main airports in Bucharest to the city centre. The current budget constraints facing Romania and the general economic climate may though delay the initial schedule for taking these projects forward.

\subsection{Integration for metro}

In Table 4 an overview of key elements of the integration for the Bucharest Metro is provided.

\subsection{Patronage and modal split effects}

An overview of passenger trends for the Bucharest Metro is provided in Table 5. Overall, usage declined significantly between 1995 and 2004, as observed by Ecorys [8]. A key factor behind this decline was identified as being lack of ticket integration between the Bucharest Metro and other forms of public transport (trams, buses and trolleys). This problem is currently being addressed as a new contactless card valid for both metro and surface public transport (RATB operations) was introduced in 2006. 
Table 4: $\quad$ Copenhagen metro - integration.

\begin{tabular}{|c|c|}
\hline Integration element & Remarks \\
\hline Information & $\begin{array}{c}\text { Information about maps, fares, timetables are } \\
\text { available. When a metro train approaches a station } \\
\text { information is given about possible bus and tram } \\
\text { connections (in the new rolling stock). Network } \\
\text { maps are gradually being introduced instead of the } \\
\text { line-specific maps only. }\end{array}$ \\
\hline Ticketing & $\begin{array}{c}\text { Ticketing integration was identified as a problem } \\
\text { between Metro and surface public transport. } \\
\text { However, this issue is being addressed with the } \\
\text { introduction of cards valid on both Metro and } \\
\text { RATB services. }\end{array}$ \\
\hline Network & $\begin{array}{c}\text { Metro network provides possibilities to transfer } \\
\text { between different lines as well as to bus, tram and } \\
\text { train. Signage was a problem but is gradually being } \\
\text { improved to enable easier transfer. }\end{array}$ \\
\hline Wider integration & $\begin{array}{c}\text { Taxis are usually available at metro stations. } \\
\text { Bicycles are used to a more limited extent in } \\
\text { Bucharest than Copenhagen. This may be an area } \\
\text { for further improvement. }\end{array}$ \\
\hline
\end{tabular}

Table 5: $\quad$ Bucharest Metro patronage, passengers, 1995 - 2009.

\begin{tabular}{|c|c|c|c|c|c|c|}
\hline & 1995 & 2004 & 2006 & 2007 & 2008 & 2009 \\
\hline $\begin{array}{c}\text { Passengers } \\
(\mathrm{mln})\end{array}$ & 160,000 & 117,000 & 141,808 & 164,782 & 182,129 & 170,888 \\
\hline
\end{tabular}

Sources: Metrorex [3] and Ecorys [8].

Note: Passenger figures for 1995 and 2004 are from the Ecorys report [8] while remaining figures were available from the Metrorex annual report.

Some 500,000 passengers on average use the Bucharest Metro and it has a share of public transport demand of around $20 \%$.

\subsection{Wider economic implications of metro}

The Bucharest Metro is providing one of the key facilitator for passenger trips in the Metropolitan areas. This is particular the case for trips going to / from City Centre destinations. As such it supports the economic activities and serves as an important mode of transport for commuter, business and leisure trips. However, recent work suggests that ongoing metro network extensions should be particularly focussed on the South zone of Bucharest in order to have a stronger positive influence on accessibility. This should be followed by extensions in the West and North zones (Dragu et al. [9]). Obviously, these extensions would have to be validated within economic feasibility studies. 


\section{Concluding remarks}

This paper has provided an overview of metro systems in Europe with particular focus on the Bucharest and Copenhagen Metros. Copenhagen Metro is one of newest metros in Europe, whereas the first line in Bucharest opened more than 30 years ago. As a result the systems are different. Metros are having an important role to play in both cities. Three key issues appear to be of particular importance regarding the planning and operation of metros:

- Limit the possibility for cost overruns and overestimation of demand through improved planning and forecasting

- Network configuration to ensure that the system provides a high level of accessibility to areas/zones that are important for the economic activities of the city

- Integration of the metro within the wider public transport system taking into account that integration is multifaceted

\section{References}

[1] International Association of Public Transport (UITP), Light Rail and Metro Systems in Europe Current market, perspectives and research implications, UITP Study report for ERRAC, 2004.

[2] Flyvbjerg, B., Cost Overruns and Demand Shortfalls in Urban Rail and Other Infrastructure, Transportation Planning and Technology, February 2007, Vol. 30, No. 1, pp. 9 - 30.

[3] MVV Consulting, Preparation of a Green Paper on Urban Transport: Report on urban transport in Europe, Prepared for the European Commission, DG TREN, 2007.

[4] Metroselskabet, Annual Report 2009, Annual Report from Metroselskabet (entity owning the Copenhagen Metro), 2010.

[5] Sputnic, Funding a Metro through land development: Ørestad, Case study report as part of the EU FP6 research project SPUTNIC.

[6] Ildensborg-Hansen, J. \& Vuk, G., Transport Impacts of the Copenhagen Metro, Proceedings of the 2006 Transport Days Conference, 2006.

[7] Metrorex, Activity Report 2009 - 2010, 2010.

[8] Ecorys, Country Report Romania, Study on Strategic Evaluation on Transport Investment Priorities under Structural and Cohesion funds for the Programming Period2007-2013 for DG REGIO, 2006.

[9] Dragu, V., Stefănică, C. \& Burciu, Ş, The Influence of Bucharest's Metro Network Development on Urban Area Accessibility, Theoretical and Empirical Researches in Urban Management, Volume 6, Issue 1 / February 2011. 